\title{
Cultural Reasons: The Most Important Factors in Resisting Wearing a Mask
}

\author{
Amir Vahedian-Azimi ${ }^{1}$, Somayeh Makvandi ${ }^{2}$, Leila Karimi ${ }^{3^{*}}$ \\ ${ }^{1}$ Trauma Research Center, Nursing Faculty, Baqiyatallah University of Medical Sciences, Tehran, Iran \\ ${ }^{2}$ Department of Midwifery, Faculty of Nursing and Midwifery, Ahvaz branch, Islamic Azad University, Ahvaz, Iran \\ ${ }^{3}$ Behavioral Sciences Research Center, Lifestyle Institute, Nursing Faculty, Baqiyatallah University of Medical Sciences, \\ Tehran, Iran \\ *Corresponding Author: Leila Karimi, PhD, Assistant Professor, Behavioral Sciences Research Center, Lifestyle \\ Institute, Nursing Faculty, Baqiyatallah University of Medical Sciences, Tehran, Iran. Tel: +98-9126860702, Email: \\ leilakarimi1487@gmail.com
}

Received July 24, 2020; Accepted July 28, 2020; Online Published August 9, 2020

\section{Dear Editor,}

One of the most important harms that threatens the world is the coronavirus. The virus has somehow affected all human biological functions such as economic relations, political decisions, and cultural actions. All the people of the world are in a bad economic situation, politicians make their decisions based on coronavirus statistics. Coronavirus has limited social relations and many customs have disappeared in the shadow of coronavirus. Unfortunately, in the second wave of coronavirus, the number of deaths has increased. ${ }^{1}$ To combat coronavirus, prevention is the best thing we can do by following health protocols. The most extensive reviews of worldwide studies also published in the Lancet Medical Journal have indicated the significant preventive impact of physical distance and the use of masks on the transmission process of the new coronavirus. ${ }^{2}$

Elements of the script in this new epidemic frame thus become frequently washing your hands, keeping a distance from others, wearing a mask, and yielding your forehead for a temperature check anytime that you enter the place of business or a housing area. Some of these elements also become semiotics in themselves; the wearing of a mask in particular (being the most visible) is a communicative act, and a declaration of solidarity, telling others that you are both in the frame and the fight. ${ }^{3}$

The studies confirm the effects of wearing a face mask and emphasize its effectiveness. According to studies, if an infected person and others wear a mask, the risk of contracting the virus for non-infected people is $79 \%{ }^{4}$ Another study in the United States and China found that countries that imposed masks earlier, such as Singapore, Taiwan, and South Korea, were much better able to prevent the spread of the crown. ${ }^{5}$

The "father" of China's public health system, Wu Lyon, advocated the widespread use of masks to protect against airborne pneumonia from the 1910 pneumonic plague that spread throughout Manchuria. This was the "function of medical wisdom and health modernity". 6 When the Spanish flu broke out in 1917, masks were introduced around the world, including in the United States and Canada. Canadian provinces and many American cities even apply masks in public. In Hong Kong, for example, wearing a mask became very common after the 2003 SARS outbreak. $^{7}$

Despite the importance of wearing face masks in preventing COVID-19, unfortunately in some societies, there are objections to its use that have been mentioned as lack of awareness of the effectiveness of masks to protect against disease, economic barriers such as the high price of masks, and physical issues like heat intolerance, and shortness of breath. Some other problems in preparing the mask, one can guess why some people still do not use this method of prevention to protect themselves and others. ${ }^{8}$

The cultural context plays a key role in the use of masks by people whose attitude towards wearing masks arises from this cultural context, thus wearing masks in the community is a kind of cultural behavior and consequently, cultural resistance is the most important obstacle compared to other obstacles. ${ }^{9}$ This resistance is especially evident when compared to East Asian countries, where wearing a mask is a "confirmation of civic mindset and work conscience," and there are reasons why wearing a mask is normal, ${ }^{3}$ as Ed Young writes in the Atlantic, wearing such masks was a common part of Chinese culture although the absence of these norms has been the biggest obstacle in Canada; in other words, seeing an individual wearing a mask causes panic as people suspect that she or he is sick. ${ }^{9}$ In Canada, masks invite stigma. Until recently, a medical mask would

Copyright (C 2020 The Author(s). This is an open-access article distributed under the terms of the Creative Commons Attribution License (http:// creativecommons.org/licenses/by/4.0), which permits unrestricted use, distribution, and reproduction in any medium, provided the original work is properly cited. 
have meant that you were sick; therefore, people would reject you. In the West, because of the strong resistance and belief in the importance of showing face, people tend to have negative ideas about masks". ${ }^{10}$

Some cultures are more obsessed with self-care measures to support society. However, in many European countries and the United States, face masks can be used to race and incite East Asian racial behavior, some businesses have unmasked signs, while officials in major Chinese cities including Beijing and Shanghai have forced people to wear face masks in public. But there is evidence that things are changing. Not only do we see more masks in public, but what it shows is changing, it seems to be a show of solidarity, not just an act of self-preservation. This epidemic has shown how culture can change so quickly. As we continue to take new steps, we can change the conception of using masks that used to mean something else to people. Empty streets are no longer tedious, and a phone call is considered as a thought-based action. And instead of a sign that everything is out of control, masks have become a sign of a retreat control. ${ }^{11}$

Fear of an epidemic could temporarily reduce culturally conscious resistance to masks, but in a broader context, it would be very difficult to "change this profound aspect of culture" as people tend to seek scientific evidence to support or disprove their previous ideas about masks. Mask has also entered the realm of behaviorism. Some believe that using a face mask can be a clear reminder of the dangers of the virus and a "behavioral flip" for everyone to maintain their hygiene". ${ }^{12}$

Because health and medical professionals as well as researchers believe that the use of masks is effective in preventing the spread of coronavirus, institutionalizing this culture is a necessity and a duty for society, which should be like a seat belt for everyone while driving. Masks and preventative measures should become a social behavior in communities, families, and the workplace. We must use health protocols such as covering a common culture.

\section{Authors' Contributions}

All authors contributed equally to this study.

\section{Conflict of Interest Disclosures}

The authors declare that they have no conflicts of interest.

\section{Ethical Approval}

Not applicable.

\section{References}

1. Strzelecki A. The second worldwide wave of interest in coronavirus since the COVID-19 outbreaks in South Korea, Italy and Iran: a google trends study. Brain Behav Immun. 2020; 88:950-951. doi:10.1016/j.bbi.2020.04.042.

2. Cheng VC, Wong SC, Chuang VW, et al. The role of communitywide wearing of face mask for control of coronavirus disease 2019 (COVID-19) epidemic due to SARS-CoV-2. J Infect. 2020;81(1):107-114. doi:10.1016/j.jinf.2020.04.024.

3. Algrim J. China's War on COVID-19: An Ethnographic Snapshot. Boston: University of Massachusetts; 2020.

4. Javid B, Weekes MP, Matheson NJ. Covid-19: should the public wear face masks? BMJ. 2020;369:m1442. doi:10.1136/bmj. m1442.

5. Buchwald E. What we Can Learn from South Korea and Singapore's Efforts to Stop Coronavirus (Besides Wearing Face Masks). MarketWatch website. 2020. https://www. marketwatch.com/story/what-we-can-learn-from-south-koreaand-singapores-efforts-to-stop-coronavirus-in-addition-towearing-face-masks-2020-03-31.

6. Yong E. Everyone Thinks They're Right About Masks. The Atlantic; 2020. https://www.theatlantic.com/health/ archive/2020/04/coronavirus-pandemic-airborne-go-outsidemasks/609235/.

7. Siu JY. Qualitative study on the shifting sociocultural meanings of the facemask in Hong Kong since the severe acute respiratory syndrome (SARS) outbreak: implications for infection control in the post-SARS era. Int J Equity Health. 2016;15:73. doi:10.1186/ s12939-016-0358-0.

8. Zhong BL, Luo W, Li HM, et al. Knowledge, attitudes, and practices towards COVID-19 among Chinese residents during the rapid rise period of the COVID-19 outbreak: a quick online cross-sectional survey. Int J Biol Sci. 2020;16(10):1745-1752. doi:10.7150/ijbs.45221.

9. Young E. How the Pandemic Will End. The Atlantic; 2020. https://www.theatlantic.com/health/archive/2020/03/how-willcoronavirus-end/608719/.

10. World Health Organization (WHO). Coronavirus Disease (COVID-19) Advice for the Public: When and How to Use Masks. WHO; 2020.

11. Garber M. Refusing to Wear a Mask Is an Empty Act of Defiance. The Atlantic; 2020. https://www.theatlantic.com/ culture/archive/2020/05/face-mask-videos-culture-warstrump-logic/612139/.

12. Taylor DB. For Black Men, Fear That Masks Will Invite Racial Profiling. The New York Times. May 26, 2020. https://www. nytimes.com/2020/04/14/us/coronavirus-masks-racismafrican-americans.html. 